\title{
Biomechanics of Cantilevered Implant-Supported Prosthesis (Biomechanics in Implant Prosthodontics)
}

\author{
José H. Rubo and Vinicius Cappo Bianco \\ Department of Prosthodontics, Bauru School of Dentistry, \\ University of São Paulo, Bauru, SP; \\ Brazil
}

\section{Introduction}

The peculiar characteristic of an implant-supported prosthesis is the fact that its fixation is given by the connection of an alloplastic material (the implant) to a living tissue (the bone). This fixation has been defined as rigid and clinically asymptomatic and must be maintained during functional loading (Albrektsson \& Zarb, 1993). Under load, bone tissue will undergo a remodeling process, which ultimately influences the long-term function of a dental implant system (Meijer et al., 1993). Bone remodelling is a complex process that involves a sequence of chemical- and mechanical-mediated biologic events known as mechanotransduction (Duncan \& Turner, 1995).

Because the occlusal load will be transferred to the implants and subsequently to the bone, it is believed that the biomechanics of the implant-supported prosthesis play an important role in the longevity of the bone around dental implants (Skalak, 1985). It is commonly found in the literature that, for cantilevered implant supported mandibular prosthesis, stresses tend to be concentrated at the cortical bone on the disto-lingual aspect of the implant closest to the load (Meijer et al., 1993; Murphy et al., 1995; Rubo \& Souza, 2008; Sertgoz \& Guvener, 1996; Weinberg \& Kruger, 1995). Many researchers have focused on the steps of force transfer to gain insight into the biomechanical effect of force directions, force magnitudes, prosthesis type, prosthesis material, implant design, number and distribution of supporting implants, bone density, and the mechanical properties of the bone-implant interface (Sahin \& Cehreli, 2002). The resultant stresses should be kept below the failure stress limit of the materials involved (Frost, 1994; Skalak, 1985; Wiskott \& Belser, 1999).

Failures in dental implant prostheses have been correlated with biomechanical complications. Overloading factors may negatively influence implant longevity (Kim et al., 2005). According to Isidor (2006), although it has been stated that occlusal forces may be associated with the loss of oral implants, a causative relationship has never been convincingly demonstrated. The related mechanisms of these displacements are still not completely understood and studies about the influences of the several biomechanical factors are inconclusive (Rangert et al., 1989). Implant failure caused by overload has been classified as a dogma and as such should be abandoned (Carlsson, 2009). There are contradictory studies regarding bone loss in overload conditions. From those studies it can be inferred that 
bone loss around implants could happen with large occlusal interferences or in the coexistence of small interferences associated with inflammation (Oh et al., 2002).

According to Brunski, (1991), three tasks need to be accomplished in implant biomechanical studies: 1) identify and quantify the biomechanical variables that can affect bone biology; 2) measure the effects of these variables quantitatively and with precision; and 3) to distinguish the effects resultant of one variable from the effects resultant of other variable. Failure prevention demands testing and stress analysis of the implants and tissues in vitro as well in vivo.

The first attempt to solve the biomechanical problem was presented by Skalak (1983), who created a mathematical model to determine force components in implants. Skalak's model considered bone and prosthesis as being infinitely rigid, while implants were considered elastic. Although this model had some limitations, part of the results are still valid and have called the attention of researchers to the biomechanical problems of implant prosthesis.

However, stress transmission to the bone must be studied taking into account bone biology aspects. During function, bone around implants is subjected to repetitive loading. Like other rigid materials, bone is subjected to fatigue. Repetitive load may result in micro fractures that, if left to build up, can lead to structural failure. The effect of tension on bone tissue has been object of discussion. The concept that bone architecture is determined by induction of tension/deformation remounts to the 19th century (Chamay \& Tschantz, 1972; Duncan \& Turner, 1995; Rieger et al., 1990). Today it is believed that changes in bone structure are the result of a system where local mechanic signals induce bone cell activity. Frost (1994) proposed a theory according to which there is a minimal bone tension level, the "minimal effective strain" (MES), above which adaptative response would take place, while below it bone would remain stable (Duncan \& Turner, 1995).

How much load implants can withstand without jeopardizing the surrounding bone is the question that remains unanswered (Brunski, 1991, 1992; Clelland et al., 1991; Murphy et al., 1995; Sertgoz \& Guvener, 1996). Although Frost's theory establishes a minimal effective strain for each loading condition, certainly there is not a single answer to the question, since individual particularities are determinants in this quantification. There is a general agreement that a well-planned and executed prosthesis is essential to avoid excessive forces on bone and implant components. Implant dentistry would greatly profit if it were provided the means to predict how bone and implant components would behave considering each patient's unique jaw anatomy, quality of bone, amount of occlusal force exerted on the prosthesis, etc.

To shed light on this issue, the influence of factors such as the curvature of the mandible, the density of cancellous bone, the length of implants and abutments, the length of cantilever, the number of implants, and the framework stiffness have been objects of study (Bidez \& Misch, 1992; Meijer et al., 1993; Pierrisnard et al., 2003; van Oosterwick 1998).

\section{FEA studies}

The creation of a computerized model of an implant-supported fixed prosthesis allows an analysis of the possible variation in stress distribution that is likely to occur with diverse prosthetic designs and occlusal load variables. A good understanding of how each component of the implant prosthesis behaves under load could facilitate optimal prosthesis design and fabrication. This could decrease the likelihood of mechanical failures as well as improve implant prosthesis longevity. 
Finite-element analysis (FEA), with all its inherent limitations (Brunski, 1988; Murphy et al., 1995), is a valuable instrument in pursuing that goal. When associated with clinical findings and accumulation of reliable data on implant loading, bone-implant contact area and other factors, FEA models could help us understand the problems encountered in daily practice (Brunski, 1991). For the reasons above mentioned, FEA studies results have to be seen with a critical eye, and the values should not be taken as absolute but rather be used to compare the possible magnitudes of stress that bone and implant components undergo during function (Meijer et al., 1993; Murphy et al., 1995; Weinberg \& Kruger, 1995).

To study some of the variables that affect the biomechanics of implant prosthodontics, a computerized 3-dimensional (3-D) finite-element model of the anterior segment of a human mandible provided with an implant-supported bridge was created. The basic model consisted of a curved beam with radius $15.0 \mathrm{~mm}$ and dimensions $69.0 \mathrm{~mm}$ long, $14.0 \mathrm{~mm}$ high, and $6.0 \mathrm{~mm}$ wide. This beam was covered with a 1.0-mm-thick layer on the buccal, occlusal, and lingual surfaces and a 3.0-mm layer at the base to simulate cortical bone. The final external dimensions were therefore $71.0318 .038 .0 \mathrm{~mm}$, respectively. Five 10.0-mm cylinders $3.75 \mathrm{~mm}$ in diameter were placed at the center of the beam, their centers $7.0 \mathrm{~mm}$ apart from each other. The cylinders were provided with 3.0-mm-high extensions to simulate the abutments. A second beam $(71.034 .036 .0 \mathrm{~mm})$ was added in connection to the abutments to simulate a framework (Figure 1).

The model was fixed at both ends for the sake of the stress analysis. All materials, bone included, were assumed to be linearly elastic and isotropic. An FEA program (I-DEAS Structural Dynamics Research, Milford, Ohio) installed in a desktop computer was used to analyze the many possible variations in prosthetic design and occlusal load.

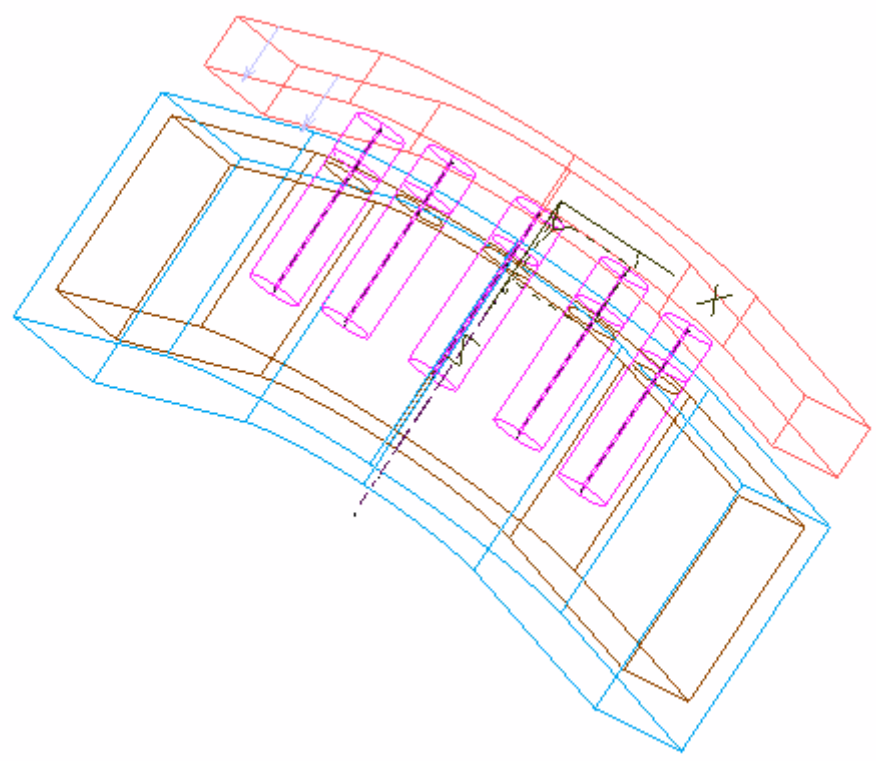

Fig. 1. 3-D model with its internal layers 
The model was fed with elastic properties of the materials as derived from the literature. Elastic modulus for cortical bone was assumed to be $13.7 \mathrm{GPa}$, while for cancellous bone it was assumed to be $1.5 \mathrm{GPa}$ based on a density of $25 \%$. A $100-\mathrm{N}$ vertical load was applied at $15.0 \mathrm{~mm}$ distally to the terminal abutment to simulate the occlusal force. Images with the fringes of stress were obtained for each of the components of the model, and maximum Von Mises stresses (oEmax) at each site were analyzed for comparison.

Seven clinical variables were chosen to be evaluated and are summarized in Table 1 for easy reference. Each variable was introduced alternately on the basic model, all other conditions being equal. Cantilever length was defined as the position where load was applied relative to the center of the terminal abutment. Quality of cancellous bone was expressed in terms of its modulus of elasticity (E) as derived from the literature. Abutment and implant lengths were based on the Brånemark system (Nobel Biocare AB, Goteborg, Sweden). Framework alloy was selected according to the modulus of elasticity of $\mathrm{AgPd}(\mathrm{E}=95 \mathrm{GPa})$ and $\mathrm{CoCr}(\mathrm{E}$ $=218 \mathrm{GPa}$ ) alloys.

\begin{tabular}{|c|c|c|c|c|}
\hline 1) curvature of mandible & ${ }^{*} \mathrm{r}=15 \mathrm{~mm}$ & $\mathrm{r}=10 \mathrm{~mm}$ & $\mathrm{r}=18 \mathrm{~mm}$ & \\
\hline 2) cantilever length & *15 mm & $10 \mathrm{~mm}$ & $20 \mathrm{~mm}$ & \\
\hline 3) cancellous bone quality & ${ }^{*} \mathrm{E}=1.5 \mathrm{Gpa}$ & $\mathrm{E}=4.0 \mathrm{GPa}$ & $\mathrm{E}=7.9 \mathrm{GPa}$ & \\
\hline 4) abutment length & $* 3.0 \mathrm{~mm}$ & $5.5 \mathrm{~mm}$ & $7.0 \mathrm{~mm}$ & \\
\hline 5) implant length & *10mm & $13 \mathrm{~mm}$ & $15 \mathrm{~mm}$ & \\
\hline 6) framework alloy & ${ }^{*} \mathrm{E}=95 \mathrm{GPa}$ & $\mathrm{E}=218 \mathrm{GPa}$ & & \\
\hline 7) number of implants & *a)5 & b) 4 & c) 4 & d) 3 \\
\hline
\end{tabular}

E - elastic modulus $\mathbf{r}$ - radius * Features of the basic model

Table 1. Clinical variables selected for analysis.

The curvature of the mandible in the anterior region is related to its shape and ultimately influences the distribution of the implants in a more curved or straight line. Apparently there is an increase in stress concentration with the wider model since the implants tend to be located in a straight line creating an unfavorable mechanical situation. For conditions like that it is advisable to keep shorter cantilever arms to avoid torsion moments that could increase stress in bone and also pushes components, particularly the screws, to risk of fracture.

From the studies we conducted with FE analysis (Rubo \& Souza, 2008, 2010) (Figures 2 to 7) it was possible to observe that the relative physical properties of the materials substantially affect the way stresses are distributed: 1 . At each increment of $5 \mathrm{~mm}$ in cantilever length, stress increased by approximately $30 \%$ to $37 \%$ on the cortical bone around implants. 2 . The stiffer the cancellous bone, the more stress it takes and the less stress the cortical bone appears to undergo. 3. A slight decrease in stress was observed with longer implants and abutments. 4 . The use of a CoCr alloy contributes to a better stress distribution.

The conventional design of an implant supported fixed bridge on the edentulous mandible results in bilaterally cantilevered framework extensions, which under load create torque and moment on the implants. Many suggestions have been made in the literature regarding the extension of the cantilever, but in general the various authors agree that according to the quality of bone, a range of 10 to $20 \mathrm{~mm}$ of cantilever extension is acceptable. Perhaps one of the most compelling findings of this and other studies is the fact that the increase in cantilever length has a remarkable impact upon the stress concentration around the implants. The longer the cantilever arm, the more stress was observed. 
Fortunately, this is one of the implant-supported prosthesis features most easily controlled by the dentist. The applications of the shortened dental arch concept and the express recommendation to the dental technician to keep the length of the cantilever arm to a minimum are procedures that cannot be neglected. Previous studies have demonstrated that the increase in cantilever length is directly proportional to the increase in stress concentration around the implants. Kunavisarut et al. (2002) observed that the presence of a cantilever arm significantly increased the stress in the prosthesis, implant, and surrounding bone. Besides, when no proper fit is achieved, the stress is magnified by the cantilever.

The effect of increasing the cantilever arm in this study was remarkable. Stress in the abutment/implant almost doubled when the force was moved from 10 to $20 \mathrm{~mm}$ along the cantilever. When analyzing the effect on the framework, a different pattern is observed. The stress increases from 10 to $15 \mathrm{~mm}$ but then decreases at the 15 to $20 \mathrm{~mm}$ change. According to Benzing et al. (1995) the load application in a framework for implant prosthesis produces deformation energy in the system that causes flexion. If a great amount of deformation energy is consumed by the framework, reduction of the transmitted energy happens, decreasing the stress in this structure.

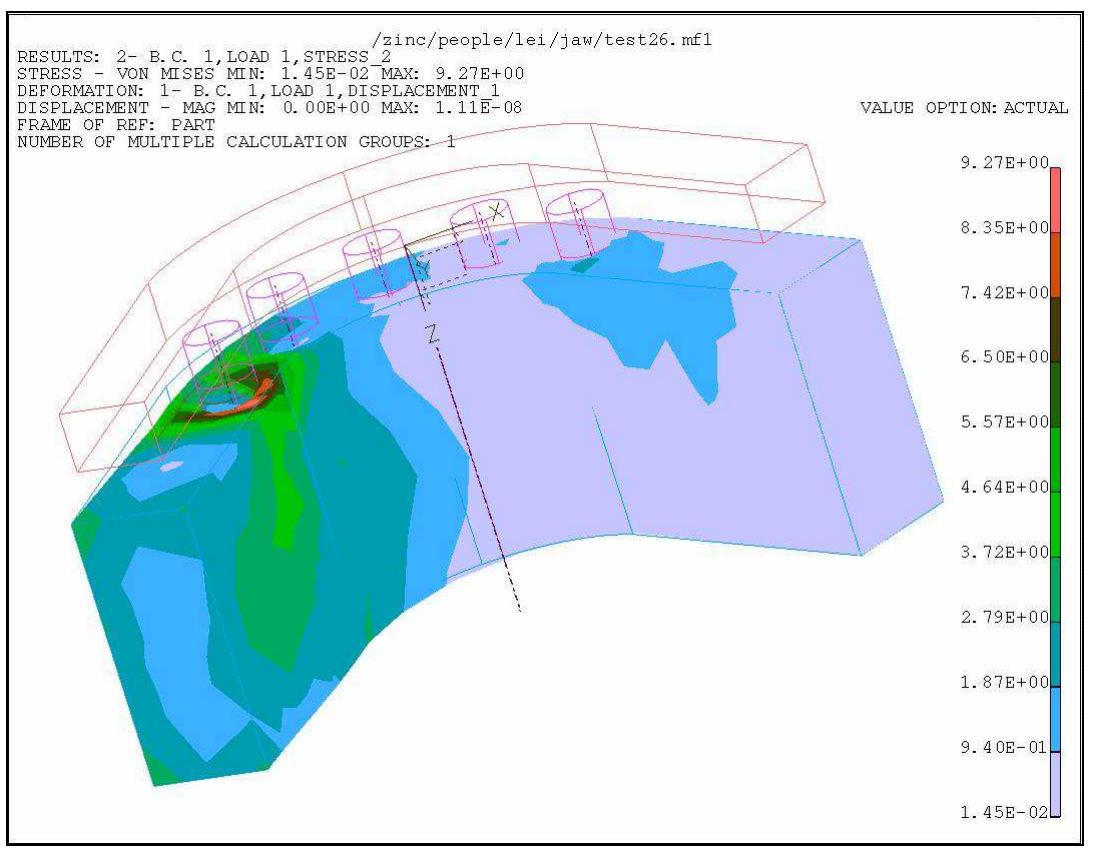

Fig. 2. Fringes of stress in cortical bone (MPa). 


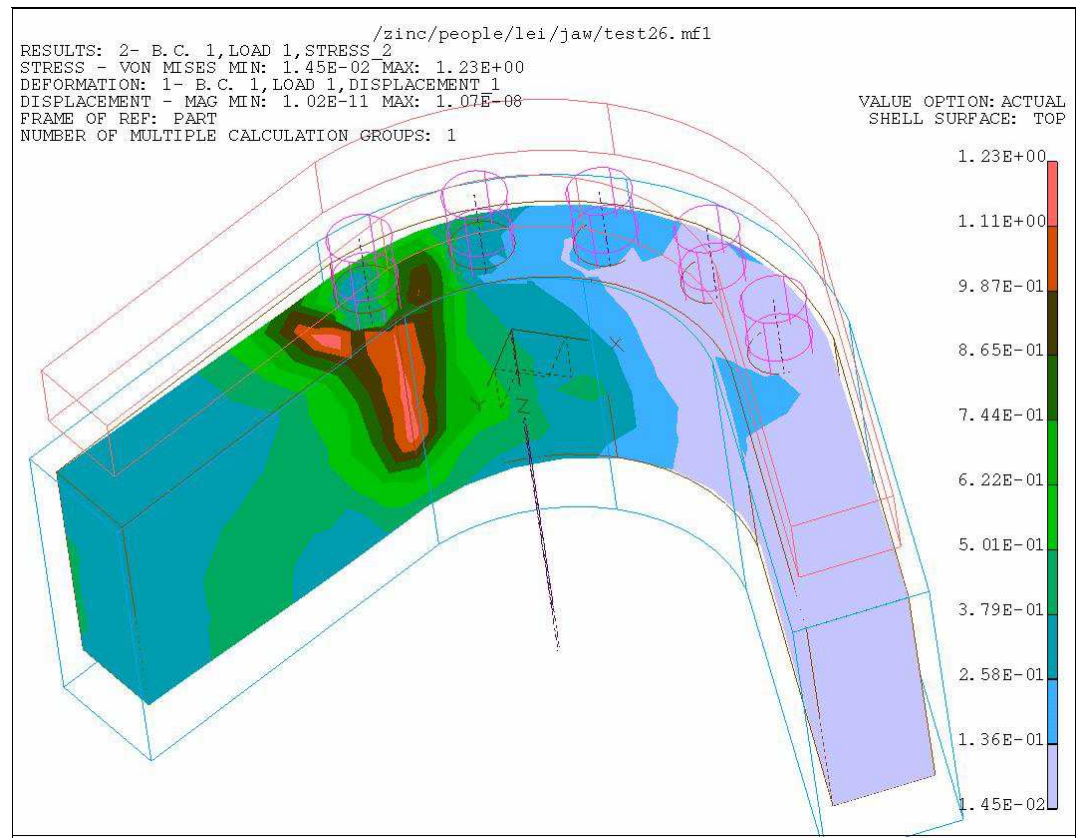

Fig. 3. Fringes of stress in cancellous bone (MPa)

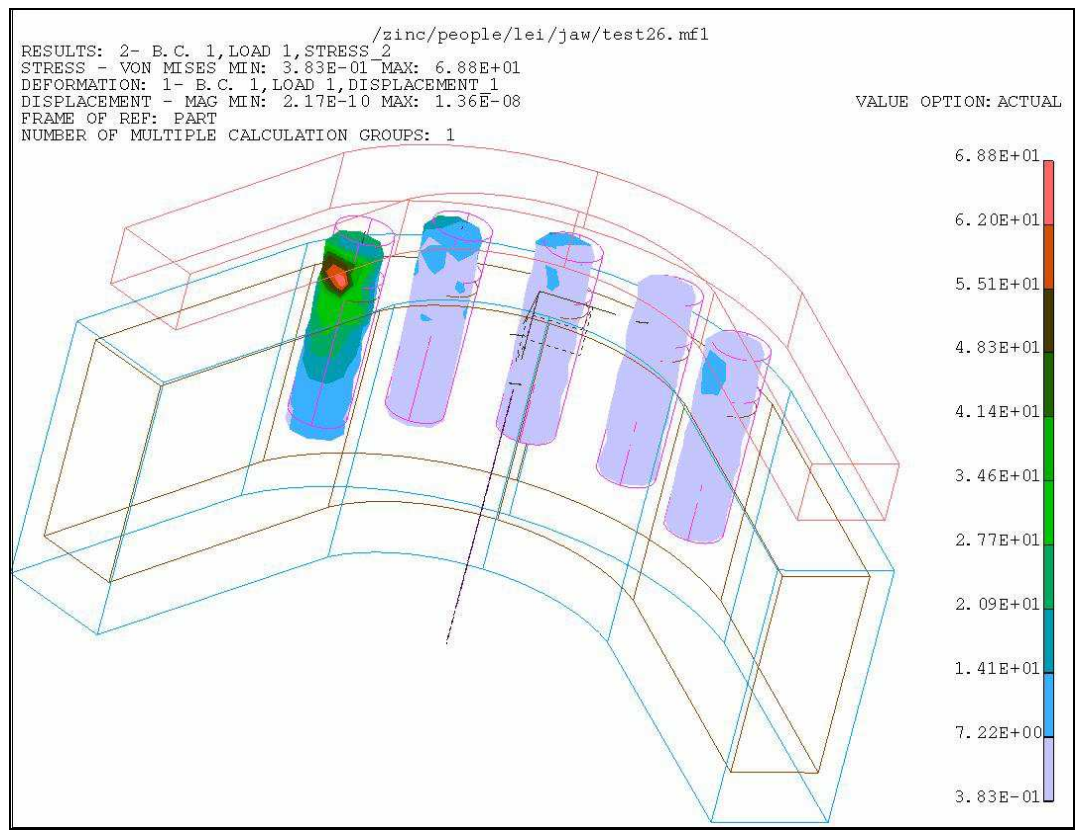

Fig. 4. Stresses on implants/abutments (lingual view). 


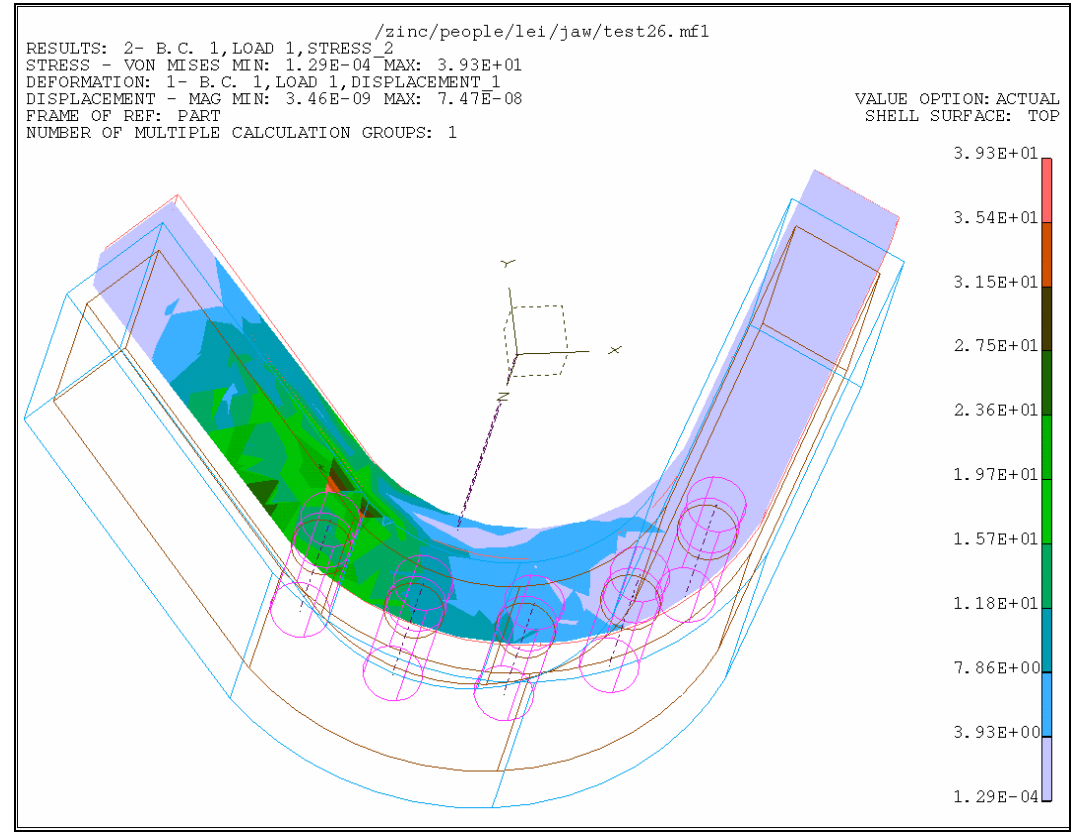

Fig. 5. Stresses on the framework (bottom view).

Structural strength is dependent on the elastic modulus, shape, and length of the prosthesis, which may affect the load distribution among the implants. The lower the elastic modulus, the greater the force applied to the abutment/implant closest to the load. Therefore, if an imaginary rubbery framework was used, nearly the totality of the load would be concentrated at the implant/abutment closest to the point of load application (Skalak, 1983). Likewise, an infinitely rigid framework would distribute the load equally among the implants. Brunski, (1992) compared two implant prosthesis frameworks of considerably different elastic moduli, one made out of acrylic resin and one made out of AgPd alloy, confirming the theory that most of the load concentrates on the terminal implant closest to the load. This finding opposes the original theory proposed by Skalak (1993) who underestimated the load on the implant closest to the load and super estimated the load on the implants on the opposite side, exactly because disregarded the mechanical properties of the structures.

The use of a CoCr alloy allowed a better stress distribution. There was an increase of the stress on the terminal abutment opposite to the load of the order of $135 \%$, with a decrease of the stress in the remaining positions. This finding is corroborated by others in the literature (Benzing et al., 1995; Hulterstrom \& Nilsson, 1994; Sertgoz \& Guvener, 1996; Skalak, 1985), who found that a stiffer framework provides a more even distribution of forces among the abutments, decreasing the stress within the retaining screws, as a result of the reduced bending of the framework. Left aside the difficulties in the use of $\mathrm{CoCr}$ alloys, like casting shrinkage (around 2.3\%) and melting point differences relative to gold cylinders, its use has been clinically tested with no complications that could be regarded to the alloy itself (Hulterstrom \& Nilsson, 1994). 
The analysis of the stress in the framework with different cantilever length revealed an interesting fact relative to the AgPd alloy: the increase in cantilever length is not followed by a proportional increase in stress levels of the framework. The stress in the framework increases when the cantilever changes from 10 to $15 \mathrm{~mm}$, but this effect does not repeat at the 15 to $20 \mathrm{~mm}$ change. In fact, there is a decrease in the stress levels, denoting that, with longer cantilevers, the framework begins to bend, yielding to the load. Benzing et al. (1995) observed that the resistance to the deformation of a golden framework was two-thirds of that of a nonprecious alloy framework. Therefore, it can be suggested that, in cases of long cantilevers, there would be a benefit in the use of a more rigid framework. Nevertheless, excessive long cantilevers must be avoided even with frameworks of high elastic modulus. When the osseointegration technique was introduced the standard procedure was the placement of six implants between the mental foramina to support a fixed prosthesis. Because of space limitations, this number was subsequently decreased to five and then to four implants without greatly compromising the distribution of stress. However, when an implant is lost, not only the number of remaining implants must be considered, but also their distribution in order to guarantee that the stresses are going to be properly dissipated (Figures 4,6 and 7). Reducing the number of implants from five to four and then three implants resulted in an increase of stresses on the abutment nearest to the point of load application $(6.88 \mathrm{MPa}$ with 5 implants, $71.2 \mathrm{MPa}$ with 4 implants and $7.72 \mathrm{MPa}$ with 3 implants). Also, the position of the implant that eventually is lost, for example the terminal implant, results in an even longer cantilever arm what could cause unpredictable consequences to the bone and components.

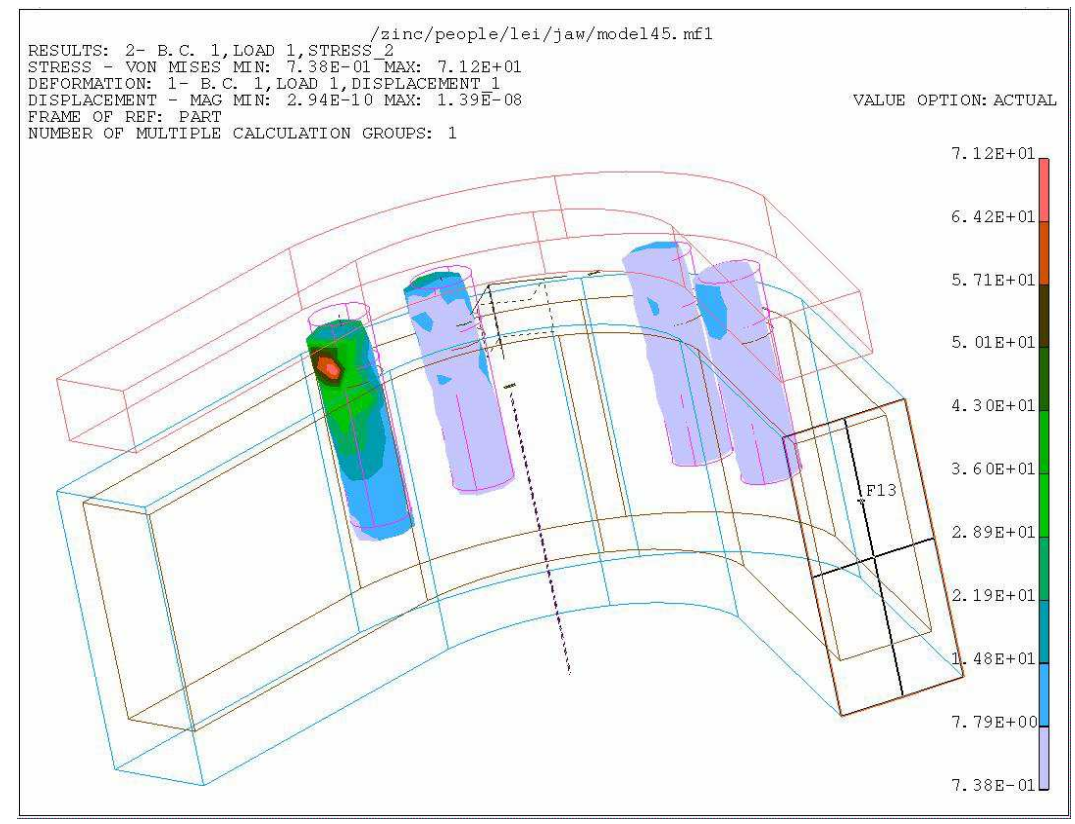

Fig. 6. Stresses on implants/abutments with four implants. 


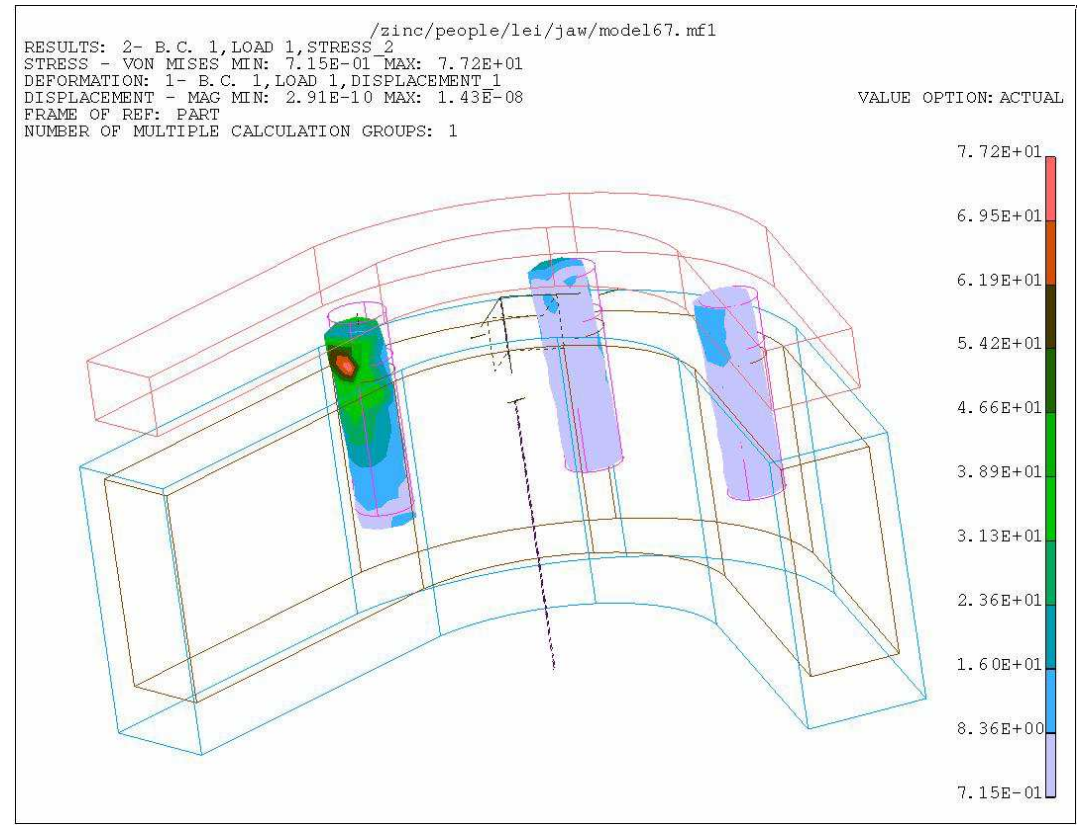

Fig. 7. Stresses on implants/abutments with three implants.

\section{Strain gauge analysis}

The relevance of osseointegration in today's prosthodontic practice is well recognized. Failure rates are low and easily surmounted by the improvements in function, esthetics, and quality of life. Nevertheless, failures do occur and are considered to be related to a range of biologic and mechanical factors. Among the most commonly reported failures are: resorption of the peri-implant bone crest, peri-implantitis, loss of osseointegration, screw loosening and fracture, and fracture of the prosthesis, prosthetic components, and even the implant itself (Jemt 1991; Kallus \& Bessing, 1994; Worthington, 1987; Zarb \& Schimitt, 1990). Many times the cause of failure is attributed to a non passive framework, which leads to implant overload (Adell et al., 1981; Carlson B, Carlsson, 1994; Patterson et al., 1995; Sahin \& Cehreli, 2001; Zarb \& Schimitt, 1990; Zitzmann \& Marinello, 2002).

Framework passivity has become a concern in implant prosthodontics and all efforts have been made to pursue it. Restorative dentists have the task of obtaining a passive fit without any accepted clinical parameters for horizontal, vertical, or angular discrepancies. Thus, the goal is to create a fit as accurate as it is clinically possible to avoid strains in the components. Therefore, the way passivity of fit is understood leads to the belief that no stresses or strains must exist at all. But that may not be true, since when torque is applied to bring the joints together a tensile force appears on the screw, which is then elongated. This leads to the development of a compressive axial force between the cylinder and abutment, which maintains the union between the components (Isa \& Hobkirk, 1995; Duyck \& Naert 2002; Geng et al., 2001).

Compressive forces deform the components to a measurable level. If the compressive force is homogeneous along the periphery of the abutment-cylinder interface or, in other words, if 
the cylinder fits properly to the abutment, deformation of the abutment should also be homogeneous and measurable. Usually, machined components are preferred to cast ones because casting may produce a rough surface, making it even more difficult to achieve a proper fit. Machined cylinders need to be overcast to create multiple element frameworks, which is another complicating factor in itself.

Hitherto, no method has been described to establish a reliable parameter for passive fit. Photoelasticity, finite element analysis, and strain gauge measurements have been proposed as tools to determine stresses/strains in implant prostheses. With the purpose of determining a measurable parameter to what constitutes a passive fit framework, a study (Moretti-Neto et al., 2009) was conducted aiming at the evaluation of the deformation to which abutments are submitted when free-standing cylinders are screwed onto them. Strain gauges were used to define the mean level of abutment deformation that can be expected with no interference of factors, such as laboratory procedures, in passive fit. The magnitude of the values found was minimal. The highest mean value of deformation was $-625.35 \mu \varepsilon$ for abutment screw tightening. Conversion to the percentage of deformation yields the value of $0.062 \%$ deformation. It should also be observed that low levels of abutment deformation do not necessarily represent a desirable condition. In fact, deformation levels close to 0 may indicate that the components are completely apart and consequently, not transmitting any force to one another. In this instance, the prosthetic screw and the framework would be overloaded, and the framework adaptation would be forced by the torque applied to the screws (Duyck et al., 2001).

The results of this study corroborate the findings of Isa \& Hobkirk (1995) who demonstrated that screw tightening generated compression and tension stresses on the abutments, even when using a framework with a misfit as small as $10 \mu \mathrm{m}$. Considering a system formed by a screwed joint, only compression forces should affect the abutments in an ideal condition of passive fit. However, tension forces were observed on the machined cylinders. These results may have occurred because the prosthesis does not establish a homogeneous and uniform contact with the surfaces of the abutments and may have presented adequate fit only at one side (Duyck et al., 2001; Clelland et al., 1993).

Horizontal and angular internal misfits, whose detection is difficult, may also contribute to the instability of the screws and generate tension forces on the implant components (Sahin \& Cehreli, 2001; Millington \& Leung, 1995; Helldén \& Dérand, 1998; Tan et al., 1993). Such distortions, which are difficult to detect, may be responsible for the variability of the results observed in this and other studies. The method employed for evaluating passive fit of prosthetic cylinders to the abutments as a function of abutment deformation could be regarded as useful, since it revealed that despite the small magnitude of the outcomes, some amount of deformation is always present and is measurable, varying from 173.29 $\mu \varepsilon$ (Pd-Ag machined cylinders) to $200.47 \mu \varepsilon$ (Co-Cr cast cylinders).

There is still a difficulty to overcome to apply these parameters to the clinical situation: It is technically difficult to connect strain gauges to patients' mouths to take measurements, which would give more reliable results. Therefore, the proposed method must be regarded as a source of information for what can be expected in an ideal condition. Variations on the amount of abutment deformation and the presence of tension forces should be related to poor quality fit of frameworks.

The clinical relevance of this study relies on the importance of understanding the mechanisms of force transmission from the framework/prosthetic cylinders to the 
abutments, from these to the implants, and consequently, to the surrounding bone. In this study, the abutments were rigidly fixed to a metallic master cast simulating the bone. Since bone is the living tissue that ultimately responds to the stresses in the system, a model that takes into account the mechanical properties of bone needs to be developed to quantify bone stress after implant prosthesis connection.

Therefore, studies have been conducted on simulated bone models. Polyurethane was found to present elastic modulus similar to human bone (Miyashiro et al., 2011; Moretti-Neto et al., 2011) and was chosen to verify the tension levels that are developed around implants during function (Figure 8) When prosthetic restorations were connected to the abutments, the tension levels on the bone located at the cervical area of the implant were very low, around $58 \mu \varepsilon$ to $100 \mu \varepsilon$ for single crowns and reaching $350 \mu \varepsilon$ to $400 \mu \varepsilon$ for multiple element restorations. What can be regarded as relevant in these studies is that the tension levels fall within physiologic limits, as proposed by Frost's minimal effective strain theory, between 50-200 $\mu \varepsilon$ to 1500-2500 $\mu \varepsilon$. Such tension levels would not be capable of causing bone resorption around implants (Rubo, 2010).

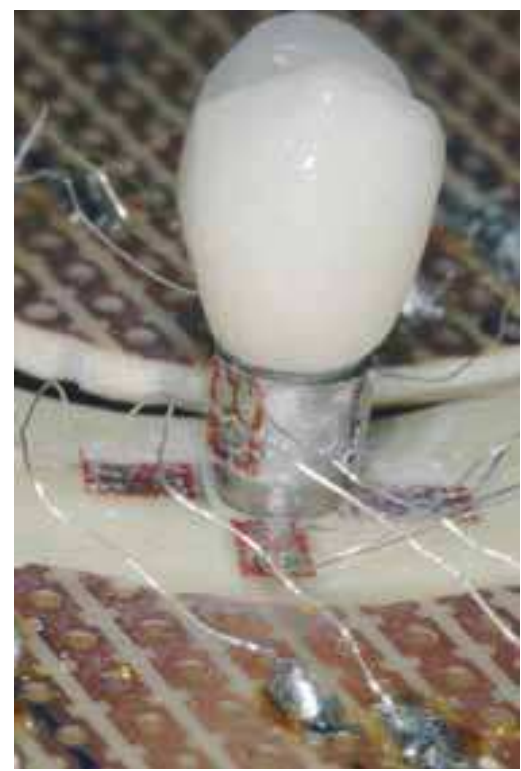

Fig. 8. A bone simulated model was used to quantify the tension around the cervical area of the implant when the restoration is connected.

The influence of cantilever length, abutment's height and framework alloy was also studied by means of strain gauge analysis (Jacques et al., 2009; Suedam et al., 2009) (Figure 9). Frameworks for implant-supported prostheses have been evolved from soldering a gold alloy framework to gold cylinders, to gold alloy frameworks cast directly onto the cylinders, to Ag-Pd alloy frameworks (Cox \& Zarb, 1985; Jemt, 1991). The clinical results showed that the latter option gives consistently good results with respect to accuracy of fit, load bearing capacity, reduced cost and design versatility (Rangert et al., 1989). However, the use of an alloy with higher modulus of elasticity, such as $\mathrm{Co}-\mathrm{Cr}$, would allow for a more 
evenly distributed load among implants with a less bulky framework, which would be an advantage if intraoral space is limited (Hulterstrom \& Nilsson, 1994; Chao et al., 1988). For these reasons, the Ag-Pd alloy framework was chosen for comparison purposes.

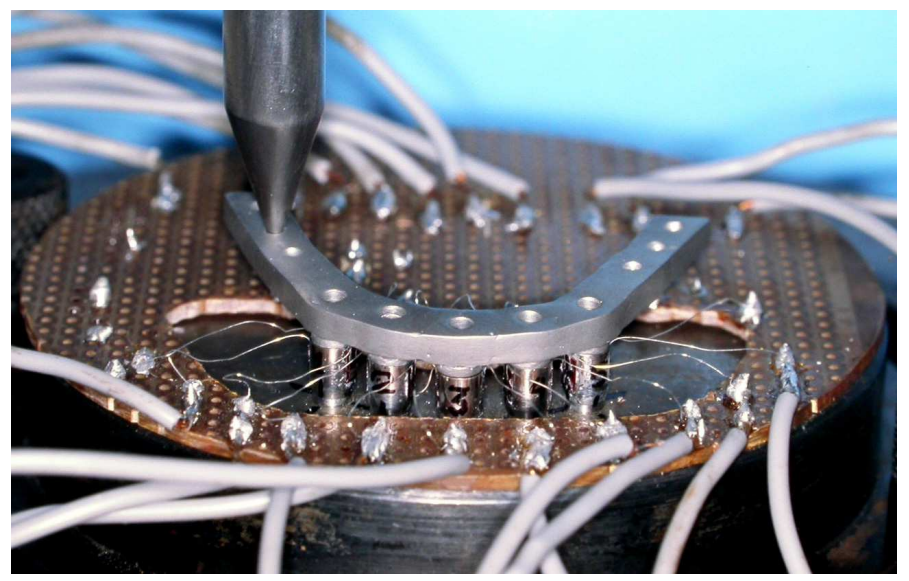

Fig. 9. A framework was screwed to the abutments with strain gages on the proximal aspects; $100 \mathrm{~N}$ load applied at $5 \mathrm{~mm}, 10 \mathrm{~mm}$ and $20 \mathrm{~mm}$ distal to terminal implant.

Cantilevered ends of fixed implant-supported prostheses increase the load on the first implant nearest the cantilever arm. In this study it could be noticed that the abutment closest to the point of load application on the cantilever extension registered deformation by compression, but higher levels of deformation by tension were observed in intermediary abutments. These results are according to data from other experiments (Benzing et al., 1995; Chao et al., 1988; Rubo \& Souza, 2008; Skalak 1983; Suedam et al., 2009) reporting that in cantilevered prostheses, the most distal implants represent the fulcrum and, therefore, are subjected to compression forces while intermediary abutments suffer tension. For the alloy with lower elastic modulus, as the distance between the point of load application and the distal abutment increases, energy is consumed in framework deflection and low deformation levels are observed in abutments.

The results of this study showed that the pattern of deformation generated by the application of the static force varied according to the position of the strain gauges in the abutment's aspects, according to the implant position relative to the load application, to the abutment's height and also to the type of alloy used for the framework. The increase of the abutment's height promoted an increase of the deformation by compression in the strain gauges located in the abutment adjacent to the cantilever. This could be explained by the increase of the lever arm that takes place with the increase of the abutment's height leading to the deformation in the abutment adjacent to the point of load application.

The strains generated in the abutments did not present a uniform pattern among the abutment's aspects and not even in different abutments. However, deformations by compression are present in a larger intensity in the strain gauges located in abutment no. 1 closest to the point of load application in all specimens, evidencing that the abutment's proximity to the load influences the results. This brings about the importance of evaluating the implant adjacent to the lever arm, concerning its bony support, for planning the extension of the cantilever. 
In Figs 10 and 11, a tendency line was added to help visualize the effect of the difference in elastic modulus of the alloy in the pattern of deformation of the framework. It clearly shows that the stiffer CoCr alloy framework is less affected by the load, resulting in compression on both ends and tension in the middle. On the other hand, the PdAg alloy framework showed a tendency to a more complex deformation pattern, resultant of its lower elastic modulus compared with the CoCr alloy framework.

\section{Group I - CoCr}

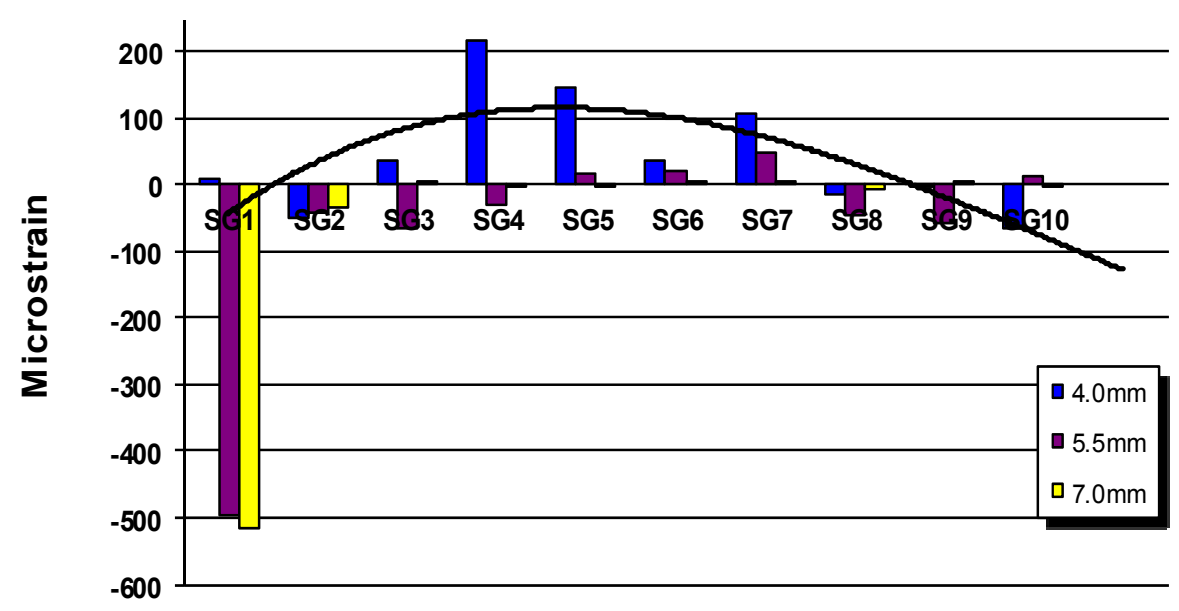

Fig. 10. Graphic of the deformation means captured by the abutment's strain gauges for CoCr frameworks.

\section{Group II - PdAg}

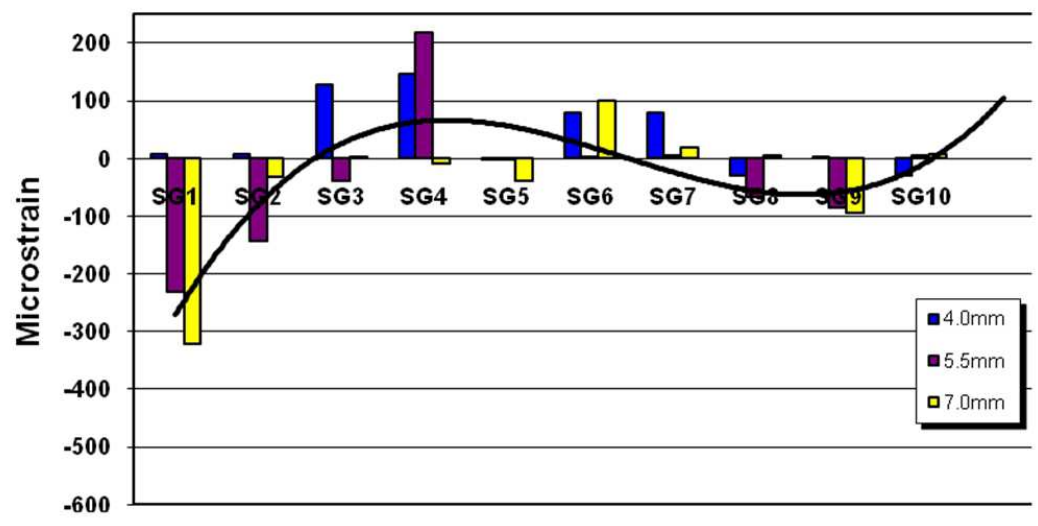

Fig. 11. Graphic of the deformation means captured by the abutment's strain gauges for PdAg frameworks. 
On the other hand, the alloy with high modulus of elasticity undergoes few or no deflection with the increase of the cantilever, resulting in more abutment deformation. In both situations, the screws can be overloaded what underscores the need to keep a reduced cantilever arm, as this has been demonstrated to be the major cause of mechanical problems (Shackleton, 1992). The results observed with both alloys are inconclusive as to what material performs better.

Clearly, there is a difference in the mechanical behavior of the two frameworks and the resultant pattern of abutment deformation, but the relevance of this finding would only be determined by clinical comparative studies. (1) Abutment deformation was always higher with longer cantilever extensions; (2) The Co-Cr alloy framework resulted in higher levels of abutment deformation; (3) The pattern of abutment deformation was different for both alloy frameworks with a tendency to tension forces to appear closer to the load when Pd-Ag alloy was used. In this study it was concluded that (1) the abutment adjacent to the cantilever presented the largest deformation by compression captured by the strain gauges, (2) the type of alloy used for fabricating the framework influenced the deformation of the abutments and (3) the increase of the abutment's height increased the deformation on the terminal abutment.

\section{Conclusion}

Many studies have been made to present solutions or explanations to the biomechanical problems in implant prosthodontics. A large bulk of knowledge can be extracted from those studies, but it seams clear that most of the loading problems are not capable of generating bone resorption, which seems to be related to other biological events.

However, overload may be responsible for many events of screw loosening and fractures, resulting in the need for more frequent maintenance. Solving these problems may be time consuming and creates additional costs.

The professional must comply with sound concepts of good prosthodontic practice to improve prostheses longevity. Obviously, most of these principles are familiar to the prosthodontist. Those are basic oral rehabilitation concepts applied in daily practice, what underscores the notion that implants are one more element added to the prosthodontist armamentarium that must be naturally incorporated to the patient's treatment plan.

\section{References}

Adell, R., Lekholm, U., Rockler, B. \& Brånemark, PI. (1981). A 15-year study of osseointegrated implants in the treatment of the edentulous jaw. International Journal of Oral Surgery Vol. 10, pp. 387-416, ISSN 0300-9785

Albrektsson, T. \& Zarb, G.A. (1993). Current interpretations of the osseointegrated response: clinical significance. International Journal of Prosthodontics Vol. 6 pp. 95-105, ISSN 0893-2174

Benzing, U.R., Gall, H. \& Weber, H. (1995). Biomechanical aspects of two different implantprosthetic concepts for edentulous maxillae. International Journal of Oral and Maxillofacial Implants Vol. 10 pp. 188-198, ISSN 0882-2786

Bidez, M.W. \& Misch, C.E. (1992). Force transfer in Implant Dentistry: basic concepts and principles. Journal of Oral Implantology Vol. 18 pp. 264-274, ISSN 0160-6972 
Brunski, J.B. (1988). Biomaterial and biomechanics in dental implant design. International Journal of Oral and Maxillofacial Implants Vol. pp. 3:85-97, ISSN 0882-2786

Brunski, J.B. (1992). Biomechanical factors affecting the bone-dental implant interface. Clinical Materials Vol. 10 pp. 153-201, ISSN 0267-6605

Brunski, J.B. (1991). Influence of biomechanical factors at the bone-biomaterial interface, In: The Bone Biomaterial Interface, $1^{\text {st }}$ ed., Davies, J.E. pp. 391-404, University of Toronto Press, ISBN 10 0802059414, Toronto.

Carlson, B. \& Carlsson, G.E. (1994). Prosthodontic complications in osseointegrated dental implant treatment. International Journal of Oral and Maxillofacial Implants Vol. 9 pp. 90-94, ISSN 0882-2786

Carlsson, G.E. (2009). Critical review of some dogmas in prosthodontics. Journal of Prosthodontic Research Vol. 53 pp. 3-10.

Chamay, A. \& Tschantz, P. (1972). Mechanical influences in bone remodelling. Experimental research on Wolff's Law. Journal of Biomechanics Vol. 5 pp. 173-180, ISSN 0021-9290

Chao, Y., Davis, D.M., Zarb, G.A. \& Judes, H. (1988). A study into the use of chromiumcobalt alloy for constructing the framework for osseointegrated prostheses. Clinical Materials Vol. 3 pp. 309-315, ISSN 0267-6605

Clelland, N.L., Gilat, A., McGlumphy, E.A. \& Brantley, W.A. (1993). A photoelastic and strain gauge analysis of angled abutments for an implant system. International Journal of Oral and Maxillofacial Implants Vol. 8 pp. 541-548, ISSN 0882-2786

Clelland, N.L., Ismail, Y.H., Zaki, H.S. \& Pipko, D. (1991). Three-dimensional finite element stress analysis in and around the Screw-Vent implant. International Journal of Oral and Maxillofacial Implants Vol. 6 pp. 391-398, ISSN 0882-2786

Cox, J. \& Zarb, G.A. (1985). Alternative prosthodontic superstructure designs. Swedish Dental Journal Vol. 28 (Suppl.) pp. 71-75, ISSN 0348-6672

Duncan, R.L. \& Turner, C.H. (1995). Mechanotransduction and the functional response of bone to mechanical strain. Calcified Tissue International Vol. 57 pp. 344-358, ISSN 0171-967X

Duyck, J. \& Naert, I. (2002). Influence of prosthesis fit and effect of a luting system on the prosthetic connection preload: an in vitro study. International Journal of Prosthodontics Vol. 15 pp. 389-396, ISSN 0893-2174

Duyck, J., Van Oosterwyck, H., Vander Sloten, J., De Cooman, M., Puers, R. \& Naert, I. (2001). Pre-load on oral implants after screw tightening fixed full prostheses: An in vivo study. Journal of Oral Rehabilitation Vol. 28 pp. 226-233, ISSN 0305-182X

Frost, H.M. (1994). Wolff's law and bone's structural adaptations to mechanical usage: an overview for clinicians. Angle Orthodontics Vol. 64 pp. 175-188, ISSN 0003-3219

Geng, J.P., Tan, K.B. \& Liu, G.R. (2001). Application of finite element analysis in Implant Dentistry: A review of the literature. Journal of Prosthetic Dentistry Vol. 85 pp. 585598, ISSN 0022-3913

Helldén, L.B \& Dérand, T. (1998). Description and evaluation of a simplified method to achieve passive fit between cast titanium frameworks and implants. International Journal of Oral and Maxillofacial Implants Vol. 13 pp. 190-196, ISSN 0882-2786

Hulterstrom, M. \& Nilsson, U. (1994). Cobalt- chromium as a framework material in implantsupported fixed prostheses: a 3-year follow-up. International Journal of Oral and Maxillofacial Implants Vol. 9 pp. 449-454, ISSN 0882-2786 
Isa, Z.M. \& Hobkirk, J.A. (1995). The effects of superstructure fit and loading on individual implant units: Part I. The effects of tightening the gold screws and placement of a superstructure with varying degrees of fit. European Journal of Prosthodontics and Restorative Dentistry Vol. 3 pp. 247-253, ISSN 0965-7452

Isidor, F. (2006). Influence of forces on peri-implant bone. Clinical Oral Implants Research Vol. 17 pp. 8-18, ISSN 0905-7161

Jacques, L.B., Moura, M.S., Suedam. V., Souza, E.A.C. \& Rubo, J.H. (2009). Effect of cantilever length and framework alloy on the stress distribution of mandibularcantilevered implant-supported prostheses. Clinical Oral Implants Research Vol. 20 pp. 737-741, ISSN 0905-7161

Jemt, T. (1991). Failures and complications in 391 consecutively inserted fixed prostheses supported by Brånemark implants in edentulous jaws: A study of treatment from the time of prosthesis placement to the first annual check up. International Journal of Oral and Maxillofacial Implants Vol. 6 pp. 270-276, ISSN 0882-2786

Kallus, T. \& Bessing, C. 1994). Loose gold screws frequently occur in full arch fixed prostheses supported by osseointegrated implants after 5 years. International Journal of Oral and Maxillofacial Implants Vol. 9 pp. 169-178, ISSN 0882-2786

Kim, Y., Oh, T.J., Misch, C.E. \& Wang, H.L. (2005). Occlusal considerations in implant therapy: clinical guidelines with biomechanical rationale. Clinical Oral Implants Research Vol. 16 pp. 26-35, ISSN 0905-7161

Kunavisarut, C., Lang, L.A., Stoner, B.R. \& Felton D.A. (2002). Finite element analysis on dental implant-supported prostheses without passive fit. Journal of Prosthodontics Vol. 11 pp. 30-40, ISSN 1059-941X

Meijer, H.J.A., Starmans, F.J.M., Bosman, F. \& Steen, W.H.A. (1993). A comparison of finite element models of an edentulous mandible provided with implants. Journal of Oral Rehabilitation Vol. 20 pp. 147-157, ISSN 0305-182X

Millington, N.D. \& Leung, T. (1995). Inaccurate fit of implant superstructures. Part 1: Stresses generated on the superstructure relative to the size of fit discrepancy. International Journal of Prosthodontics Vol. 8 pp. 511-516, ISSN 0893-2174

Miyashiro, M., Suedam, V., Moretti-Neto, R.T., Ferreira, P.M. \& Rubo, J.H. (2011). Validation of an experimental polyurethane model for biomechanical studies on implantsupported prosthesis - tension tests. Journal of Applied Oral Science Vol. 19 No. 3 pp. 134-138, ISSN 1678-7765

Moretti-Neto, R.T., Hiramatsu, D.A., Suedam, V., Conti, P.C.R. \& Rubo, J.H. (2011). Validation of an experimental polyurethane model for biomechanical studies on implant-supported prosthesis - compression tests. Journal of Applied Oral Science Vol. 19 No. 1 pp. 47-51, ISSN 1678-7765

Moretti-Neto, R.T., Moura, M.S., Souza, E.A.C. \& Rubo, J.H. (2009). Implant abutment deformation during prosthetic cylinder screw tightening: an in vitro study. International Journal of Prosthodontics Vol. 22 pp. 391-395, ISSN 0893-2174

Murphy, W.M., Williams, K.R. \& Gregory, M.C. (1995). Stress in bone adjacent to dental implants. Journal of Oral Rehabilitation. Vol. 22 pp. 897-903, ISSN 0305-182X

Oh, T.J., Yoon, J., Mish, C.E. \& Wang, H.L. (2002). The causes of early implant bone loss: myth or science? Journal of Periodontology Vol. 3 pp. 322-33, ISSN 0022-3492 
Patterson, E.A., Burguete, R.L., Thoi, M.H. \& Johns, R.B. (1995). Distribution of load in an oral prosthesis system: An in vitro study. International Journal of Oral and Maxillofacial Implants Vol. 10 pp. 552-560, ISSN 0882-2786

Pierrisnard, L., Renouard, F., Renault, P. \& Barquins, M. (2003). Influence of implant length and bicortical anchorage on stress distribution. Clinical Implant Dentistry and Related Research Vol. 5 pp. 254-262, ISSN 1523-0899

Rangert, D.F., Jemt, T. \& Jorneus, L. (1989). Forces and moments on Branemark implants. International Journal of Oral and Maxillofacial Implants Vol. 4 No.3 pp. 241-247, ISSN 0882-2786

Rangert, B., Jemt, T. \& Jorneus, L. (1989). Forces and moments on Branemark implants. International Journal of Oral and Maxillofacial Implants Vol. 4 pp. 241-247, ISSN 08822786

Rieger, M.R., Mayberry, M. \& Brose, M.O. (1990). Finite element analysis of six endosseous implants. Journal of Prosthetic Dentistry Vol. 63 pp. 671-676, ISSN 0022-3913

Rubo, J.H. \& Souza, E.A.C. (2008). Finite element analysis of stress in bone around dental implants. Journal of Oral Implantology Vol. 9 pp. 407- 418, ISSN 0160-6972

Rubo, J.H. \& Souza, E.A.C. (2010). Finite element analysis of stress on dental implant prosthesis. Clinical Implant Dentistry and Related Research Vol. 12 pp. 105-113, ISSN 1523-0899

Rubo, J.H. (2010). Biomechanical studies in implant prosthodontics. Implantnews Vol. 7 pp. 139-44, ISSN 1678-6661

Sahin, S., Çehreli, M.C. \& Yalçin, E. (2002). The influence of functional forces on the biomechanics of implant-supported prostheses - a review. Journal of Dentistry Vol. 30 pp. 271-282, ISSN 0300-5712

Sahin, .S \& Çehreli, M.C. (2001). The significance of passive framework fit in implant prosthodontics: Current status. Implant Dentistry Vol. 10 pp. 85-90, ISSN 1056-6163

Sertgoz, A. \& Guvener, S. (1996). Finite element analysis of the effect of cantilever and implant length on stress distribution in an implant-supported fixed prosthesis. Journal of Prosthetic Dentistry Vol. 76 pp. 165- 169, ISSN 0022-3913

Shackleton, J., Carr, L., Slabbert, J.C.G., Lownie, J.F. \& Becker, P.J. (1992). Prosthodontic complications and problems of fixture-supported prostheses. Journal of Dental Research Vol. 71 No. 4 pp. 1113, ISSN 0022-0345

Skalak, R. (1985). Aspects of biomechanical considerations. In: Tissue integrated prostheses Osseointegration in clinical dentistry, $1^{\text {st }}$ ed. Branemark, P-I., Zarb, G.A. \& Albrektsson, T. pp. 117-128 Quintessence, ISBN 0-86715-123-3, Chicago, IL.

Skalak, R. (1983). Biomechanical considerations in osseointegrated prostheses. Journal of Prosthetic Dentistry, Vol. 49, No. 6 pp. 843-848, ISSN 0022-3913

Suedam, V., Capello Souza, E.A., Moura, M.S., Jacques, L.B. \& Rubo, J.H. (2009). Effect of abutment's height and framework alloy on the load distribution of mandibular cantilevered implantsupported prosthesis. Clinical Oral Implants Research Vol. 20 pp. 196-200, ISSN 0905-7161

Tan, K.B., Rubenstein, J.E., Nicholls, J.I. \& Yuodelis, R.A. (1993). Three-dimensional analysis of the casting accuracy of one-piece, osseointegrated implant-retained prostheses. International Journal of Prosthodontics Vol. 6 pp. 346-363, ISSN 0893-2174

van Oosterwick, H., Duyck, J., Vander Sloten, J., Van der Perre, G., De Cooman, M., Lievens, S., et al. (1998). The influence of bone mechanical properties and implant fixation 
upon bone loading around oral implants. Clinical Oral Implants Research Vol. 9 pp. 407-418, ISSN 0905-7161

Weinberg, L.A., Kruger, B. (1995). A comparison of implant/prosthesis loading with four clinical variables. International Journal of Prosthodontics Vol. 8 pp. 421-433, ISSN 0893-2174

Wiskott, H.W.A. \& Belser, U.C. (1999). Lack of integration of smooth titanium surfaces: a working hypothesis based on strains generated in the surrounding bone. Clinical Oral Implants Research Vol. 10 pp. 429-444, ISSN 0905-7161

Worthington, P., Bolender, C.L. \& Taylor, T.D. (1987). The Swedish system of osseointegrated implants: Problems and complications encountered during a 4-year trial period. International Journal of Oral and Maxillofacial Implants Vol. 2 pp. 77-84, ISSN 0882-2786

Zarb, G.A. \& Schimitt, A. (1990). The longitudinal clinical effectiveness of osseointegrated dental implants: The Toronto study. Part II: The prosthetic results. Journal of Prosthetic Dentistry Vol. 64 pp. 53-61, ISSN 0022-3913

Zitzmann, N.U. \& Marinello, C.P. (2002). A review of clinical and technical considerations for fixed and removable implant prostheses in edentulous mandible. International Journal of Prosthodontics Vol. 15 pp. 65-72, ISSN 0893-2174 


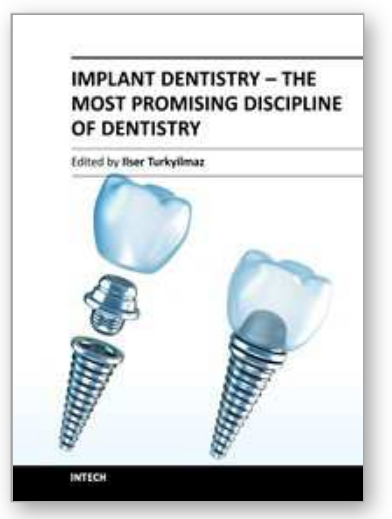

\author{
Implant Dentistry - The Most Promising Discipline of Dentistry \\ Edited by Prof. Ilser Turkyilmaz
}

ISBN 978-953-307-481-8

Hard cover, 476 pages

Publisher InTech

Published online 30, September, 2011

Published in print edition September, 2011

Since Dr. Branemark presented the osseointegration concept with dental implants, implant dentistry has changed and improved dramatically. The use of dental implants has skyrocketed in the past thirty years. As the benefits of therapy became apparent, implant treatment earned a widespread acceptance. The need for dental implants has resulted in a rapid expansion of the market worldwide. To date, general dentists and a variety of specialists offer implants as a solution to partial and complete edentulism. Implant dentistry continues to advance with the development of new surgical and prosthodontic techniques. The purpose of Implant Dentistry - The Most Promising Discipline of Dentistry is to present a comtemporary resource for dentists who want to replace missing teeth with dental implants. It is a text that integrates common threads among basic science, clinical experience and future concepts. This book consists of twenty-one chapters divided into four sections.

\title{
How to reference
}

In order to correctly reference this scholarly work, feel free to copy and paste the following:

José H. Rubo and Vinicius Cappo Bianco (2011). Biomechanics of Cantilevered Implant-Supported Prosthesis (Biomechanics in Implant Prosthodontics), Implant Dentistry - The Most Promising Discipline of Dentistry, Prof. Ilser Turkyilmaz (Ed.), ISBN: 978-953-307-481-8, InTech, Available from:

http://www.intechopen.com/books/implant-dentistry-the-most-promising-discipline-of-dentistry/biomechanicsof-cantilevered-implant-supported-prosthesis-biomechanics-in-implant-prosthodontics-

\section{INTECH}

open science | open minds

\section{InTech Europe}

University Campus STeP Ri

Slavka Krautzeka 83/A

51000 Rijeka, Croatia

Phone: +385 (51) 770447

Fax: +385 (51) 686166

www.intechopen.com

\section{InTech China}

Unit 405, Office Block, Hotel Equatorial Shanghai

No.65, Yan An Road (West), Shanghai, 200040, China

中国上海市延安西路65号上海国际贵都大饭店办公楼 405 单元

Phone: +86-21-62489820

Fax: $+86-21-62489821$ 
(C) 2011 The Author(s). Licensee IntechOpen. This chapter is distributed under the terms of the Creative Commons Attribution-NonCommercialShareAlike-3.0 License, which permits use, distribution and reproduction for non-commercial purposes, provided the original is properly cited and derivative works building on this content are distributed under the same license. 